\title{
Glasgow prognostic score predicts prognosis of non-small cell lung cancer: a meta-analysis
}

\author{
Lucheng Zhu ${ }^{1,2,4 \dagger}$, Sumei Chen ${ }^{3,4 \dagger}$, Shenglin Ma $a^{1,2,3^{*}}$ and Shirong Zhang ${ }^{1,2^{*}}$
}

\begin{abstract}
Objective: Glasgow prognostic score (GPS), an inflammation-based scoring system, has been evaluated in various cancers. However, its clinical significance remains unclear in non-small cell lung cancer (NSCLC). Therefore, it is necessary to conduct a meta-analysis to explore the prognostic value of GPS in NSCLC patients.

Methods: A quantitative meta-analysis was performed through a systematic search in PubMed, Web of Science, and the Cochrane Library. The pooled hazard ratios (HRs) of overall survival (OS) were calculated and compared.

Results: A total of 12 studies comprising 2669 patients were included in this meta-analysis. Compared with GPS 0 group, patients in GPS 1-2 group exhibited a reduced OS with a pooled HR of 1.89 ( $95 \% \mathrm{Cl}$ 1.57-2.27, $p<0.001$; $R^{2}=54 \%$ ). Six studies had sufficient data to calculate HRs of OS for GPS 1 and GPS 2 groups. Analysis revealed that GPS 2 group had a statistically significant reduced OS compared with GPS 1 group with a pooled HR of $1.87(95 \% \mathrm{Cl}$ $1.18-2.97, p=0.008 ; P^{2}=72 \%$ ). Study type (retrospective vs. prospective) and disease stage could partially explain the heterogeneity of each study by subgroup analysis.
\end{abstract}

Conclusion: Pretreatment GPS could serve as a simple and reliable prognosis predictor for NSCLC. More welldesigned studies that consider GPS as a stratification factor are warranted.

Keywords: Glasgow prognostic score, GPS, Non-small cell lung cancer, Prognosis, Meta-analysis

\section{Background}

For many decades, lung cancer has been the most common cancer and the leading cause of cancer death worldwide (Ferlay et al. 2010). Non-small cell lung cancer (NSCLC) accounts for approximately $80 \%$ of lung cancer. Surgery, chemotherapy and radiotherapy are three primary treatment modalities for NSCLC. The current staging system, namely the TNM staging system, proposed by American Joint Committee on Cancer (AJCC) is widely used in clinical practice. However, the current

\footnotetext{
*Correspondence: mashenglin@outlook.com; mashenglin@medmail. com.cn; shirley4444@gmail.com

${ }^{\dagger}$ Lucheng Zhu and Sumei Chen contributed equally to this work

${ }^{1}$ Affiliated Hangzhou Hospital of Nanjing Medical University, No. 261 Huansha Road, Shangcheng District, Hangzhou 310006, People's Republic of China

${ }^{2}$ Hangzhou First People's Hospital, No. 261, Huansha Road, Shangcheng District, Hangzhou 310006, People's Republic of China

Full list of author information is available at the end of the article
}

TNM staging system is inadequate to predict prognosis. Prognosis differs in most cases, even for patients in the same stage. For example, approximately $30 \%$ of early-stage patients experienced tumor recurrence and a poor prognosis although adequate radical treatment was administered. In recent decades, systematic inflammation has been thought to play a crucial role in tumorigenesis and serve as a hallmark of cancer (Hanahan and Weinberg 2011). The Glasgow prognostic score (GPS) is an inflammation-based scoring system that is evaluated by two serum indicators: C-reactive protein (CRP) as an indicator of systematic inflammatory response and albumin, which reflects nutritional status (Bremnes et al. 2011; Liao et al. 2014; Forrest et al. 2004; Leung et al. 2012; Pinato et al. 2014). Several studies have reported the correlation between GPS and NSCLC patients; however, due to differences in the inclusion criteria of NSCLC patients and limited sample sizes undermining its role, its

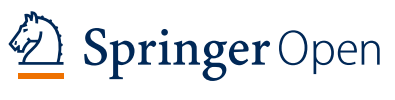

(c) 2016 Zhu et al. This article is distributed under the terms of the Creative Commons Attribution 4.0 International License (http:// creativecommons.org/licenses/by/4.0/), which permits unrestricted use, distribution, and reproduction in any medium, provided you give appropriate credit to the original author(s) and the source, provide a link to the Creative Commons license, and indicate if changes were made. 
significance in patients with NSCLC has not been fully studied. Considering that the GPS is currently widely studied for different types of cancers, including NSCLC, a systemic comparison to further clarify its clinical utility is needed. Therefore, this study aimed to explore the prognostic value of GPS in NSCLC using a quantitative meta-analysis combining all available evidence from retrospective studies.

\section{Methods}

\section{Publication search}

A systematic search was performed in PubMed, Web of Science, and the Cochrane Library from January 1, 1966 to August 31, 2015. The search strategy used both MeSH terms and free-text words to increase sensitivity. The following search terms were used: "inflammation-based score", "Glasgow prognostic score", "GPS", and "non-small cell lung cancer".

\section{Inclusion and exclusion criteria}

The following inclusion criteria were used: (1) articles investigating the relation of GPS and prognosis for NSCLC patients; (2) serum was collected before surgery or other treatments; (3) patients were grouped according to the GPS; (4) GPS 0/1/2 was defined as none/only one/both elevated CRP ( $>10 \mathrm{mg} / \mathrm{L})$ and hypoalbuminemia $(<35 \mathrm{~g} / \mathrm{L})$. The following exclusion criteria were used: (1) letters, editorials, expert opinions, case reports and reviews; (2) studies without usable data; (3) duplicate publications.

\section{Data extraction}

Two investigators independently extracted data from the eligible studies, and disagreements were resolved by discussion with a third investigator. For each study, the following information was recorded: first author, publication year, country, sample size, TNM stage, therapy, and overall survival (OS).

\section{Statistical analysis}

The hazard ratios (HRs) were extracted as described in our previous publication (Zhu et al. 2015). The procedure is briefly outlined: (1) obtain the HRs directly from the publication; HRs from multivariate analysis are an option when HRs from univariate analysis were also available; (2) estimate the HRs from O-E statistic and variance; (3) calculate the HRs from data, including the number of patients and events at risk in each group, and the log-rank statistic or the $p$ value; (4) retrieve HRs from Kaplan-Meier Curves by extracting several survival rates at specified times from the curves. Statistical analyses of HRs for OS were calculated by Review Manager Version 5.3 (Revman, the Cochrane Collaboration, Oxford, England). The heterogeneity of the data was evaluated by
Chi square $Q$ test and $I^{2}$ statistic. For the $Q$ test, a $p$ value $<0.05$ indicated significant heterogeneity; for the $I^{2}$ statistics, an $I^{2}$ value greater than $50 \%$ was considered significant heterogeneity. Statistical significance was defined as a $p$ value $<0.05$.

\section{Results}

\section{Characteristics of included studies}

As shown in Fig. 1, the electronic search yielded 226 records. After screening titles and abstracts, 23 full-text articles were assessed for eligibility. Finally, a total of 12 articles met the inclusion criteria and were included in this meta-analysis (Forrest et al. 2004; Leung et al. 2012; Pinato et al. 2014; Miyazaki et al. 2015; Kishi et al. 2015; Kawashima et al. 2015; Jiang and Lu 2015; Grose et al. 2015; Tomita et al. 2014; MacKenzie et al. 2014; Rinehart et al. 2013; Meek et al. 2010). Among these 12 articles, six were retrospective, and six were prospective studies. Six studies were from United Kingdom, four from Japan, one from China, and one from America. Details are summarized in Table 1.

\section{Association between GPS and OS}

In total, 12 studies of 2669 patients compared OS between GPS 0 and GPS 1-2 groups. The random-effects model was adopted as the significant heterogeneity $\left(I^{2}=54 \%, p=0.01\right)$. Analysis revealed a pooled HR of 1.89 with $95 \%$ CI $1.57-2.27$ ( $p<0.001$ ) (Fig. 2). Compared with GPS 0 group, patients in GPS 1-2 group had a significantly poor OS, suggesting pretreatment GPS had the ability to predict prognosis.

Six studies had sufficient data to calculate HRs of OS between GPS 1 and GPS 2 groups. Because significant

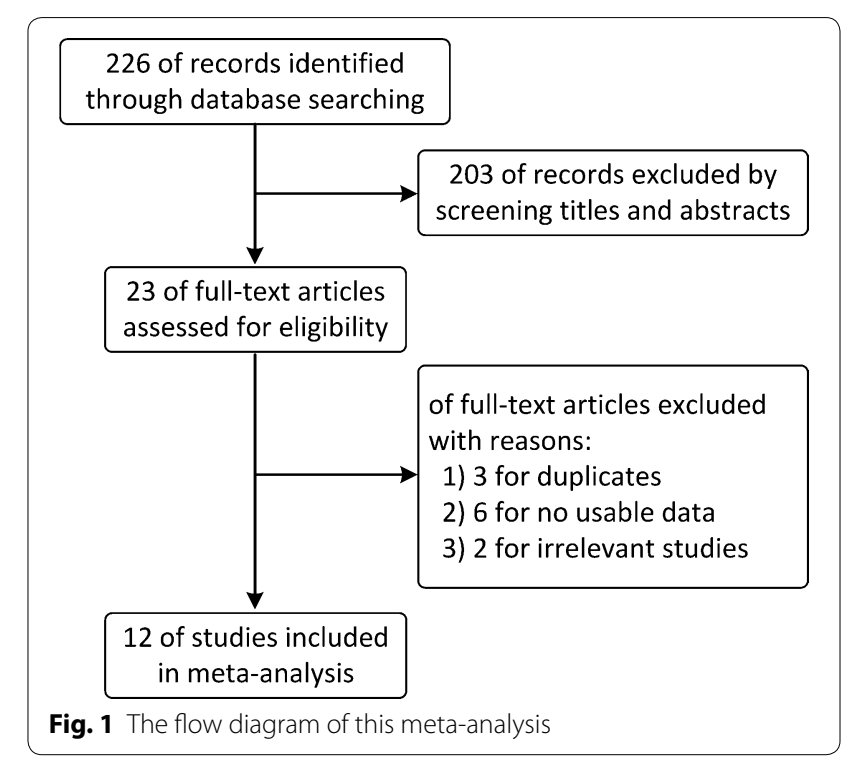


Table 1 Characteristics of studies in this meta-analysis

\begin{tabular}{|c|c|c|c|c|c|c|c|c|}
\hline \multirow[t]{2}{*}{ Study name } & \multirow[t]{2}{*}{ Region } & \multirow[t]{2}{*}{ Study type } & \multicolumn{4}{|c|}{ Sample size } & \multirow[t]{2}{*}{ Stage } & \multirow[t]{2}{*}{ Therapy } \\
\hline & & & Total & GPS 0 & GPS 1 & GPS 2 & & \\
\hline Miyazaki et al. (2015) & Japan & Retrospective & 97 & 65 & 32 & & I & Surg \\
\hline Kishi et al. (2015) & Japan & Retrospective & 165 & 100 & 65 & & । & SBRT \\
\hline Kawashima et al. (2015) & Japan & Retrospective & 1043 & 897 & 107 & 39 & $|-|||$ & Surg \\
\hline Jiang and Lu (2015) & China & Prospective & 138 & 95 & 32 & 11 & III-IV & Chemo \\
\hline Grose et al. (2015) & UK & Prospective & 120 & 50 & 49 & 21 & $|-|||$ & Surg/RT/Chemo \\
\hline Tomita et al. (2014) & Japan & Retrospective & 312 & 264 & 31 & 17 & $|-|||$ & Surg \\
\hline Pinato et al. (2014) & UK & Prospective & 220 & 131 & 39 & 29 & $|-|||$ & Surg \\
\hline MacKenzie et al. (2014) & UK & Retrospective & 97 & - & - & - & $|-|||$ & Surgery/RT \\
\hline Rinehart et al. (2013) & USA & Prospective & 51 & 9 & 32 & 10 & IV & Chemo \\
\hline Meek et al. (2010) & UK & Retrospective & 56 & 19 & 31 & 6 & Inoperable II-IV & RT/Chemo \\
\hline Forrest et al. (2004) & UK & Prospective & 109 & 27 & 69 & 13 & Inoperable III-IV & Chemo \\
\hline Leung et al. (2012) & UK & Prospective & 261 & 59 & 163 & 39 & Inoperable III-IV & RT/Chemo \\
\hline
\end{tabular}

Surg surgery, SBRT stereotactic body radiation therapy, $R T$ radiotherapy, Chemo chemotherapy

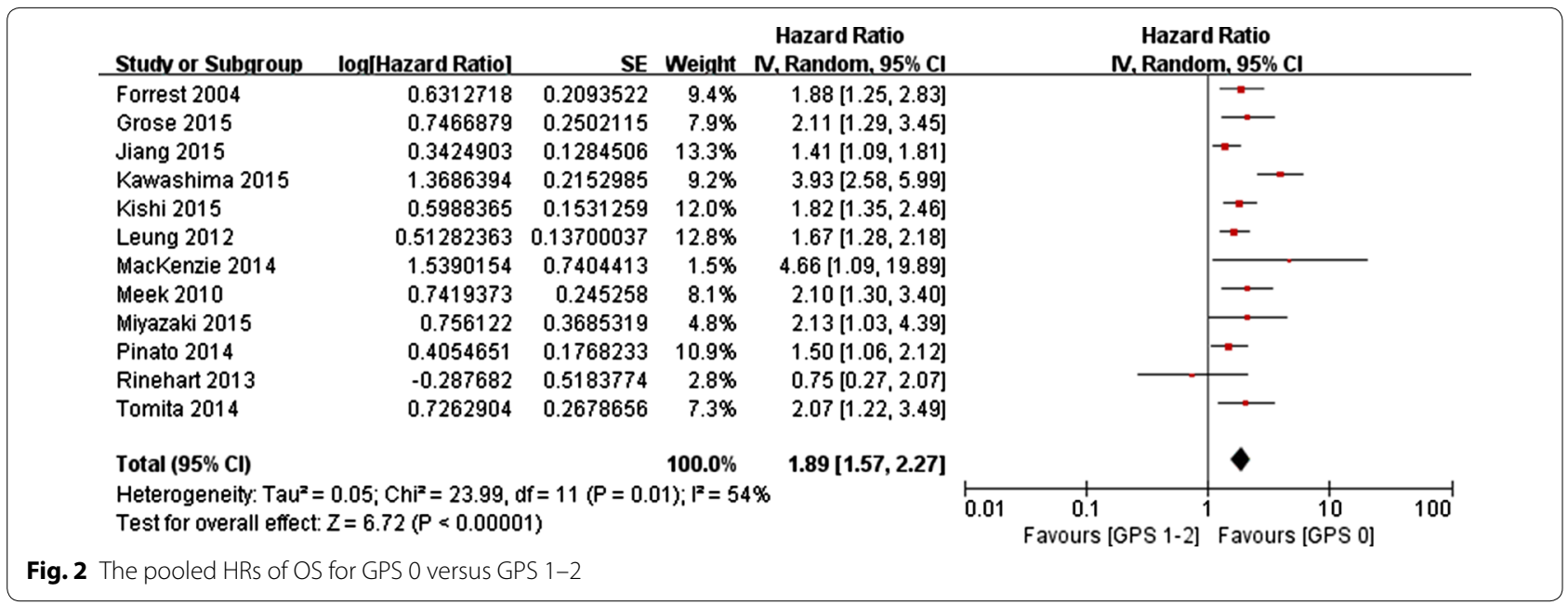

heterogeneity existed among the studies $\left(I^{2}=72 \%\right.$, $p=0.003)$, the random-effects model was adopted. Analysis revealed a pooled HR of 1.87 (95\% CI 1.18-2.97, $p=0.008$ ) (Fig. 3). GPS 1 group had a significantly prolonged OS compared with GPS 2 group, indicating an increased risk of patients with both elevated CRP and hypoalbuminemia.

\section{Subgroup analysis}

As significant heterogeneity was noted across the studies, we further investigated potential sources of heterogeneity by subgroup analysis.

We first explored the impact of study type (retrospective vs. prospective) on heterogeneity. Six retrospective studies had a pooled HR (GPS 0 vs. GPS 1-2) of 2.38 (95\% CI 1.76, 3.20) with small heterogeneity
$\left(I^{2}=49 \%, p=0.08\right)$, and six prospective studies had a pooled HR (GPS 0 vs. GPS 1-2) of 1.58 (95\% CI 1.37, $1.83)$ with small heterogeneity $\left(I^{2}=3 \%, p=0.40\right)$. Next, we explored the influence of disease stage on heterogeneity. Five studies including stage IV or inoperable patients had a pooled HR (GPS 0 vs. GPS 1-2) of 1.61 (95\% CI $1.34,1.94)$ with small heterogeneity $\left(I^{2}=21 \%, p=0.28\right)$. These results indicate that pretreatment GPS might predict prognosis well.

\section{Discussion}

The current study is a quantitative meta-analysis evaluating the prognostic value of GPS in patients with NSCLC. The pooled estimates of 12 studies involving 2669 patients indicated that patients with elevated GPS were predisposed to exhibit inferior survival outcome 


\begin{tabular}{|c|c|c|c|c|c|c|c|c|}
\hline Studv or Subgroup & log[Hazard Ratio] & SE & Weight IV. & $\begin{array}{l}\text { Hazard Ratio } \\
\text { V. Random. } 95 \% \mathrm{Cl}\end{array}$ & & $\begin{array}{r}\text { Hazard } \\
\text { IV. Randol }\end{array}$ & $\begin{array}{l}\text { d Ratio } \\
\text { m. 95\% Cl }\end{array}$ & \\
\hline Grose 2015 & 0.40129 & 0.228654 & $20.3 \%$ & $1.49[0.95,2.34]$ & & & & \\
\hline Jiang 2015 & 0.470004 & 0.400157 & $14.6 \%$ & $1.60[0.73,3.51]$ & & & & \\
\hline Kawashima 2015 & 0.122874 & 0.452973 & $13.0 \%$ & $1.13[0.47,2.75]$ & & & & \\
\hline Leung 2012 & 1.23256026 & 0.16002035 & $22.5 \%$ & $3.43[2.51,4.69]$ & & & $\rightarrow$ & \\
\hline Pinato 2014 & 0.131028 & 0.350268 & $16.2 \%$ & $1.14[0.57,2.26]$ & & & & \\
\hline Rinehart 2013 & 1.202972 & 0.442071 & $13.3 \%$ & $3.33[1.40,7.92]$ & & & & \\
\hline Total $(95 \% \mathrm{Cl})$ & & & $100.0 \%$ & $1.87[1.18,2.97]$ & & & & \\
\hline \multicolumn{5}{|c|}{$\begin{array}{l}\text { Heterogeneity: } \operatorname{Tau}^{2}=0.22 ; \mathrm{Chi}^{2}=17.74, \mathrm{df}=5(\mathrm{P}=0.003) ; \mathrm{I}^{2}=72 \% \\
\text { Test for overall effect: } Z=2.66(P=0.008)\end{array}$} & \multirow[t]{2}{*}{0.01} & \multirow[t]{2}{*}{$\begin{array}{c}0.1 \\
\text { Favours [GPS 2] }\end{array}$} & \multirow[t]{2}{*}{1 Favours [GPS 1] } & \multirow[t]{2}{*}{100} \\
\hline \multicolumn{5}{|c|}{ Fig. 3 The pooled HRs of OS for GPS 1 versus GPS 2} & & & & \\
\hline
\end{tabular}

(HR 1.87: 1.18-2.97, $p=0.008$ ). The significant relationship between GPS and OS was assessed in all the subgroup analyses stratified by the study type (retrospective vs. prospective) and different stages (early stage vs. stage IV or inoperable). The results indicate that GPS can be a practical indictor to predict NSCLC patient prognosis.

Inflammation plays an important role in tumor occurrence and development (O'Callaghan et al. 2010; Tauler and Mulshine 2009). GPS, which is an inflammationbased score combining serum CRP and albumin, was first proposed by Forrest et al. (2003). Subsequently, its clinical significance has been evaluated in various tumor types, including hepatocellular carcinoma, gastric cancer, prostate cancer, and colorectal cancer. CRP, a non-specific acute reactant protein of inflammation, is synthesized in hepatocytes and in response to release of cytokines, such as interleukin 6 release by monocytes and other immune cells under infection, tissue necrosis, and inflammatory disease (Pepys and Hirschfield 2003). As a component of the inflammatory response of the immune system, CRP exerts important role in the tumor-host interaction (Ballou and Lozanski 1992; Cermak et al. 1993), and elevated CRP is associated with impaired $\mathrm{T}$ lymphocytic response within the tumor ( $\mathrm{Du}$ Clos and Mold 2004). A meta-analysis conducted by Jing et al. (2015) indicated that elevated CRP could predict poor 5 -year OS rates ( $R R=2.15,95 \%$ CI 1.78-2.59) and 5 -year disease-specific survival rates $(R R=2.12,95 \%$ CI 1.56-2.88). Serum albumin is an important marker of nutritional status, and hypoalbuminemia is correlated with cachexia (Evans et al. 2008). Mori et al (2015). found that the prognostic nutritional index was an independent prognostic factor for completely resected NSCLC. Another study indicated that pretreatment serum albumin was an independent prognostic factor for Stage IIIB NSCLC that is associated with the response rate to firstline therapy and survival rates (Tanriverdi et al. 2015). Additionally, hypoalbuminemia is associated with treatment-induced toxicity or complications (Ataseven et al.
2015; Arrieta et al. 2010), which also may portend the poor prognosis to a certain extent.

Currently, accurate staging of the tumor is of vital importance in making a clinical decision of NSCLC. The International Association for the study of Lung Cancer (IASLC) periodically proposes revisions to the TNM staging system, and increasing data indicates information used to indicate tumor stage is inadequate (McMillan 2008). Performance status (PS) is an effective complement for tumor stage, partly reflecting patient's tolerance to treatment. For patients with poor PS, chemotherapy or radiotherapy are typically not applicable. Several large-scale studies indicate that PS is an independent prognostic factor for OS in NSCLC (Kawaguchi et al. 2010; Sculier et al. 2008; Chansky et al. 2009). However, PS is recognized to be subjective, and its reliability in predicting outcome is compromised (Ando et al. 2001). By contrast, as an objective predictor, GPS is easier to measure, routinely available and well standardized. Increasing evidence indicates that GPS has independent prognostic value in cancer patients (McMillan 2008, 2013). A study of Forrest et al. (2004) also indicated that the prognostic value of the GPS is independent of tumor stage in NSCLC with an HR of 1.88 (95 \% CI 1.25-2.84). Our data indicate that elevated GPS scores correlate with inferior survival, suggesting that the use of anti-inflammatory agents and the reinforcement of nutrition possibly may benefit the overall survival.

Nevertheless, there are several limitations in the study. The comparison between GPS 0 and GPS 1 was not performed as the relevant data were not reported in most of the included studies. Different treatment settings in studies also inevitably increased the heterogeneity. In addition, the large $\mathrm{I}^{2}$ value (54 and $72 \%$ ) reflected this dilemma and would reduce the reliability of interpreting the results. Some studies incorporating patients with small cell lung cancer were not included in our analysis (Grose et al. 2015; Gioulbasanis et al. 2012). Given that 
the number of patients included in each study for each meta-analysis was relative small and half of the included articles were retrospective studies that could generate bias by variation, a large scale prospective study that uses GPS as a stratification factor is required to reduce the bias in future.

In conclusion, as an easily obtained and reliable inflammatory index, GPS is a promising prognostic indicator in patients with NSCLC. More well-designed prospective studies are needed to promote the use of GPS in the routine clinical practice as a complementary prognostic factor for the current TNM staging system.

\section{Authors' contributions}

ZLC has been involved in drafting the manuscript and revising it critically for important intellectual content. CSM has made substantial contributions to acquisition of data, or analysis and interpretation of data. MSL and ZSR have made substantial contributions to conception and design of this manuscript. All authors read and approved the final manuscript.

\section{Author details}

${ }^{1}$ Affiliated Hangzhou Hospital of Nanjing Medical University, No. 261, Huansha Road, Shangcheng District, Hangzhou 310006, People's Republic of China. ${ }^{2}$ Hangzhou First People's Hospital, No. 261, Huansha Road, Shangcheng District, Hangzhou 310006, People's Republic of China. ${ }^{3}$ Affiliated Hangzhou First People's Hospital of Zhejiang Chinese Medical University, Hangzhou 310006, People's Republic of China. ${ }^{4}$ Hangzhou Cancer Hospital, Hangzhou 310006, People's Republic of China.

\section{Acknowledgements}

This study was supported by grants from National Natural Science Foundation of China (Grant No. 81272611 to S. M.) and Major Science and Technology Innovation Project of Hangzhou (Grant No. 20112312 A01 to S. M.), Zhejiang Medical Science Foundation of China (Grant No. 2014 KYA178 to S. Z.), Hangzhou Key Disease and Discipline Foundation of China (Grant No. 20140733 Q15 to S. Z.), and Zhejiang Provincial Natural Science Foundation of China (Grant No. LY15H160010 to S. Z.). The funders had no role in study design, data collection and analysis, decision to publish, or preparation of the manuscript.

\section{Competing interests}

The authors declare that they have no competing interests.

\section{Informed consent}

This study was approved by the Ethics Committee of Hangzhou First People's Hospital. As this study was performed on public articles, informed consents was obtained from all individual participants by each included studies.

Received: 9 October 2015 Accepted: 4 April 2016

Published online: 12 April 2016

\section{References}

Ando M, Ando Y, Hasegawa Y, Shimokata K, Minami H, Wakai Ket al (2001) Prognostic value of performance status assessed by patients themselves, nurses, and oncologists in advanced non-small cell lung cancer. Br J Cancer 85(11):1634-1639. doi:10.1054/bjoc.2001.2162

Arrieta O, Michel Ortega RM, Villanueva-Rodriguez G, Serna-Thome MG, Flores-Estrada D, Diaz-Romero C et al (2010) Association of nutritional status and serum albumin levels with development of toxicity in patients with advanced non-small cell lung cancer treated with paclitaxelcisplatin chemotherapy: a prospective study. BMC Cancer 10:50. doi:10.1186/1471-2407-10-50

Ataseven B, du Bois A, Reinthaller A, Traut A, Heitz F, Aust S et al (2015) Preoperative serum albumin is associated with post-operative complication rate and overall survival in patients with epithelial ovarian cancer undergoing cytoreductive surgery. Gynecol Oncol 138(3):560-565. doi:10.1016/j.ygyno.2015.07.005

Ballou SP, Lozanski G (1992) Induction of inflammatory cytokine release from cultured human monocytes by C-reactive protein. Cytokine 4(5):361-368

Bremnes RM, Al-Shibli K, Donnem T, Sirera R, Al-Saad S, Andersen S et al (2011) The role of tumor-infiltrating immune cells and chronic inflammation at the tumor site on cancer development, progression, and prognosis: emphasis on non-small cell lung cancer. J Thorac Oncol 6(4):824-833. doi:10.1097/JTO.0b013e3182037b76

Cermak J, Key NS, Bach RR, Balla J, Jacob HS, Vercellotti GM (1993) C-reactive protein induces human peripheral blood monocytes to synthesize tissue factor. Blood 82(2):513-520

Chansky K, Sculier JP, Crowley JJ, Giroux D, Van Meerbeeck J, Goldstraw P (2009) The International Association for the Study of Lung Cancer Staging Project: prognostic factors and pathologic TNM stage in surgically managed non-small cell lung cancer. J Thorac Oncol 4(7):792-801. doi:10.1097/JTO.0b013e3181a7716e

Du Clos TW, Mold C (2004) C-reactive protein: an activator of innate immunity and a modulator of adaptive immunity. Immunol Res 30(3):261-277. doi:10.1385/ir:30:3:261

Evans WJ, Morley JE, Argiles J, Bales C, Baracos V, Guttridge D et al (2008) Cachexia: a new definition. Clin Nutr 27(6):793-799. doi:10.1016/j. clnu.2008.06.013

Ferlay J, Shin HR, Bray F, Forman D, Mathers C, Parkin DM (2010) Estimates of worldwide burden of cancer in 2008: GLOBOCAN 2008. Int J Cancer 127(12):2893-2917

Forrest LM, McMillan DC, McArdle CS, Angerson WJ, Dunlop DJ (2003) Evaluation of cumulative prognostic scores based on the systemic inflammatory response in patients with inoperable non-small-cell lung cancer. Br J Cancer 89(6):1028-1030. doi:10.1038/sj.bjc.6601242

Forrest LM, McMillan DC, McArdle CS, Angerson WJ, Dunlop DJ (2004) Comparison of an inflammation-based prognostic score (GPS) with performance status (ECOG) in patients receiving platinum-based chemotherapy for inoperable non-small-cell lung cancer. Br J Cancer 90(9):1704-1706. doi:10.1038/sj.bjc.6601789

Gioulbasanis I, Pallis A, Vlachostergios PJ, Xyrafas A, Giannousi Z, Perdikouri IE et al (2012) The Glasgow Prognostic Score (GPS) predicts toxicity and efficacy in platinum-based treated patients with metastatic lung cancer. Lung Cancer 77(2):383-388. doi:10.1016/j.lungcan.2012.04.008

Grose D, Morrison DS, Devereux G, Jones R, Sharma D, Selby C et al (2015) The impact of comorbidity upon determinants of outcome in patients with lung cancer. Lung Cancer 87(2):186-192. doi:10.1016/j. lungcan.2014.11.012

Hanahan D, Weinberg RA (2011) Hallmarks of cancer: the next generation. Cell 144(5):646-674. doi:10.1016/j.cell.2011.02.013

Jiang AG, Lu HY (2015) The Glasgow prognostic score as a prognostic factor in patients with advanced non-small cell lung cancer treated with cisplatinbased first-line chemotherapy. J Chemother 27(1):35-39. doi:10.1179/197 3947814Y.0000000188

Jing X, Huang C, Zhou H, Li C, Fan L, Chen J et al (2015) Association between serum $\mathrm{C}$-reactive protein value and prognosis of patients with non-small cell lung cancer: a meta-analysis. Int J Clin Exp Med 8(7):10633-10639

Kawaguchi T, Takada M, Kubo A, Matsumura A, Fukai S, Tamura A et al (2010) Performance status and smoking status are independent favorable prognostic factors for survival in non-small cell lung cancer: a comprehensive analysis of 26,957 patients with NSCLC. J Thorac Oncol 5(5):620-630. doi:10.1097/JTO.0b013e3181d2dcd9

Kawashima M, Murakawa T, Shinozaki T, Ichinose J, Hino H, Konoeda C et al (2015) Significance of the Glasgow Prognostic Score as a prognostic indicator for lung cancer surgery. Interact Cardiovasc Thorac Surg. doi:10.1093/icvts/ivv223

Kishi T, Matsuo Y, Ueki N, lizuka Y, Nakamura A, Sakanaka K et al (2015) Pretreatment modified Glasgow prognostic score predicts clinical outcomes after stereotactic body radiation therapy for early-stage non-small cell lung cancer. Int J Radiat Oncol Biol Phys 92(3):619-626. doi:10.1016/j. ijrobp.2015.02.018

Leung EY, Scott HR, McMillan DC (2012) Clinical utility of the pretreatment glasgow prognostic score in patients with advanced inoperable non-small cell lung cancer. J Thorac Oncol 7(4):655-662. doi:10.1097/ JTO.0b013e318244ffe1 
Liao C, Yu Z, Guo W, Liu Q, Wu Y, Li Y et al (2014) Prognostic value of circulating inflammatory factors in non-small cell lung cancer: a systematic review and meta-analysis. Cancer Biomark 14(6):469-481. doi:10.3233/ cbm-140423

MacKenzie A, Johnson E, Tsim S, Blyth K (2014) P75 prognostic implications of the modified Glasgow prognostic score in early stage nonsmall cell lung cancer. Thorax 69(Suppl 2):A108-A109. doi:10.1136/ thoraxjnl-2014-206260.216

McMillan DC (2008) An inflammation-based prognostic score and its role in the nutrition-based management of patients with cancer. Proc Nutr Soc 67(3):257-262. doi:10.1017/s0029665108007131

McMillan DC (2013) The systemic inflammation-based Glasgow Prognostic Score: a decade of experience in patients with cancer. Cancer Treat Rev 39(5):534-540. doi:10.1016/j.ctrv.2012.08.003

Meek CL, Wallace AM, Forrest LM, McMillan DC (2010) The relationship between the insulin-like growth factor-1 axis, weight loss, an inflammation-based score and survival in patients with inoperable non-small cell lung cancer. Clin Nutr 29(2):206-209. doi:10.1016/j.clnu.2009.08.013

Miyazaki T, Yamasaki N, Tsuchiya T, Matsumoto K, Kunizaki M, Taniguchi D et al (2015) Inflammation-based scoring is a useful prognostic predictor of pulmonary resection for elderly patients with clinical stage I non-smallcell lung cancer. Eur J Cardiothorac Surg 47(4):e140-e145. doi:10.1093/ ejcts/ezu514

Mori S, Usami N, Fukumoto K, Mizuno T, Kuroda H, Sakakura N et al (2015) The significance of the prognostic nutritional index in patients with completely resected non-small cell lung cancer. PLoS One 10(9):e0136897. doi:10.1371/journal.pone.0136897

O'Callaghan DS, O'Donnell D, O'Connell F, O'Byrne KJ (2010) The role of inflammation in the pathogenesis of non-small cell lung cancer. J Thorac Oncol 5(12):2024-2036
Pepys MB, Hirschfield GM (2003) C-reactive protein: a critical update. J Clin Investig 111(12):1805-1812. doi:10.1172/jci18921

Pinato DJ, Shiner RJ, Seckl MJ, Stebbing J, Sharma R, Mauri FA (2014) Prognostic performance of inflammation-based prognostic indices in primary operable non-small cell lung cancer. Br J Cancer 110(8):1930-1935. doi:10.1038/bjc.2014.145

Rinehart J, Arnold S, Kloecker G, Lim A, Zaydan MA, Baeker T et al (2013) Phase $\|$ randomized trial of carboplatin and gemcitabine with or without dexamethasone pre-treatment in patients with Stage IV non-small cell lung cancer. Cancer Chemother Pharmacol 71(5):1375-1383. doi:10.1007/ s00280-013-2111-3

Sculier JP, Chansky K, Crowley JJ, Van Meerbeeck J, Goldstraw P (2008) The impact of additional prognostic factors on survival and their relationship with the anatomical extent of disease expressed by the 6th Edition of the TNM Classification of Malignant Tumors and the proposals for the 7th Edition. J Thorac Oncol 3(5):457-466. doi:10.1097/JTO.0b013e31816de2b8

Tanriverdi O, Avci N, Oktay E, Kalemci S, Pilanci KN, Cokmert S et al (2015) Pretreatment serum albumin level is an independent prognostic factor in patients with Stage IIIB non-small cell lung cancer: a study of the Turkish Descriptive Oncological Researches Group. Asian Pac J Cancer Prev 16(14):5971-5976

Tauler J, Mulshine JL (2009) Lung cancer and inflammation: interaction of chemokines and hnRNPs. Curr Opin Pharmacol 9(4):384-388. doi:10.1016/j.coph.2009.06.004

Tomita M, Ayabe T, Chosa E, Nakamura K (2014) Prognostic significance of preand post-operative Glasgow prognostic score for patients with non-small cell lung cancer. Anticancer Res 34(6):3137-3140

Zhu L, Liu J, Ma S, Zhang S (2015) Long noncoding RNA MALAT-1 can predict metastasis and a poor prognosis: a meta-analysis. Pathol Oncol Res 21(4):1259-1264. doi:10.1007/s12253-015-9960-5

\section{Submit your manuscript to a SpringerOpen ${ }^{\circ}$ journal and benefit from:}

- Convenient online submission

- Rigorous peer review

- Immediate publication on acceptance

- Open access: articles freely available online

- High visibility within the field

- Retaining the copyright to your article

Submit your next manuscript at springeropen.com 